\title{
Plant Layout for Small Scale Food Industry
}

\author{
Nafis Khuriyati*, Anggoro C. Sukartiko, Annisa Kartikasari \\ Department of Agroindustrial Technology, Faculty of Agricultural Technology \\ Universitas Gadjah Mada, Jl. Flora No.1 Bulaksumur 55281, Indonesia. \\ Email: nafis.khuriyati@ugm.ac.id*
}

\begin{abstract}
Small scale food industries are identical with labor intensive, low efficiency, and bad housekeeping. It needs specific improvement of performance related to their raw material characteristics as agricultural commodities. The study was conducted to improve the performance of small cracker industry through improved plant layout. It was done by considering the material flow, relationship between activities, food safety, equipment and workers' allowances, space utilization. Plant layout modification improves the small scale cracker industry in terms of material flow, the risk of contamination, space utilization, work safety, and energy for material handling.
\end{abstract}

Keywords: Crackers, energy expenditure, material handling, plant layout, small scale industry

\section{INTRODUCTION}

Small scale industries are very important in the national economy of Indonesia. The main problem is low competitiveness of those industries caused by low productivity. Therefore, it needs appropriate strategy which is effective and low cost for small scale industry. Khuriyati et al. (2014) have proposed low-cost cleaner production techniques to reduce waste and water usage significantly in small scale crackers industry. Application of the good housekeeping reduced water usage $22.04 \%$ and improved the environmental performance in terms of BOD, COD, and TSS by $76.67 \%$, $84 \%$, and $40 \%$, respectively.

Plant layout design is an important factor which can influence work efficiency. It is needed to appropriately arrange machine, workers, workstation, department, warehouse, and other production facilities to create effective plant layout. It reduces the production cycles, work-in-progress, idle times, number of bottlenecks or material handling times and increases in the production output. A good placement of that facilities contributes to the overall efficiency of operations and can reduce until $50 \%$ the total operating expenses (Tompkins et al., 2003).

Small scale industries in most cases have limited in the production area. As a consequence some of the layout principles are not met. Moreover, for the food industry since the material to be processed is intended for human consumption, the requirement such as food safety is not considered.

In this paper an attempt is made to modify the existing layout of small scale food industry in order to increase the efficiency in terms of a smooth material movement, reduce the distance of material flow, food safety, and energy for material handling.

\section{METHODS}

The food industry under study is concentrating on crackers production with an installed capacity of $900 \mathrm{~kg}$ per day. The raw materials consist of cassava flour, shrimp, fish, garlic, butter, sugar, salt, cooking oil and water. The number of workers is 11 , all male. Production runs daily 8 hours. Plant is located in Bantul Regency of Yogyakarta Special Province.

The procedure for modification of plant layout follows three steps as described;

\subsection{Analysis of the existing plant layout}

The $1^{\text {st }}$ step was to identify the problem under flow material and operation. The primary data collected regarding the dimensions of the building, area of each workstation, distance between work stations, and number of trips between workstations. The company records also have been considered to 
get vital information regarding production details, production \& sales performance, raw and supported materials which constitutes the secondary data group. The existing situation as the initial plant layout was drawn. The material handling audit check sheet referred to Tompkins (2003) interviews with concerned staff and secondary data from the production unit have been used to identify improper material handling that hinder the smooth material flow.

\subsection{Modification plant layout design}

The modification of the original layout has been attempted by considering the number of equipment/machine needed to fit the capacity; allowance for machine; worker, and material; relationship between activities. Food industry has uniqueness in their material therefore in considering relationship between activities it is needed to identify the hazard of cross contamination. These relationships is drawn in an activity relationship chart (ARC). Modification layout used BLOCPLAN that is the important method for layout design. It is an interactive program used to enlarge and improve layout. It is a simple program which generates good initial layouts due to its elasticity based on numerous imbedded options. It uses both quantitative and qualitative data to generate several block layouts and their measure of fitness. The user can choose the relative solutions based on circumstances.

Hasyim et al. (2014) have applied BLOCPLAN to modify layout of golf gloves industry. Results of the layout modification improves the smoothness of material flow with less backtracking and cross-movement, Distance is reduced to $47.31 \%$, the capacity can be increased to $20 \%$, and reduced the cost of the material handling is $31.52 \%$.

\subsection{Performance measurement of the proposed layout}

There are different parameters available to measure the effectiveness of the results obtained. Distances, flows between workstations, production time, labor cost, productivity, line balancing efficiency are few among them. The selection of these parameters depends on the uniqueness of the problems that exists in the company. The total distance between workstations and total distance traveled per day have been selected in this case. The total distance between workstations is taken as the sum of distance between workstations. Similarly the total distance traveled per day is the product of distance between 2 departments and the flow between them. The flow may be defined as the number of trips per day. Because small scale industry generally applies manual material handling, this paper proposed worker energy consumption as a performance parameter of plant layout. The energy expenditure is taken from heart rate measurement of workers. The relation between heart rate and energy expenditure is expressed in the formula as shown below (Bridger, 1995).

$$
Y=1.80411-0.0229038 X+4.71733 .10^{-4} X^{2}
$$

$Y$ : energy $(\mathrm{kcal} / \mathrm{min})$

$X$ : heart rate (beat $/ \mathrm{min})$

Energy consumption for work:

where,

$$
K E=E t-E i
$$

$K E$ : energy consumption ( $\mathrm{kcal} / \mathrm{min})$

$E t$ : Energy expenditure during work $(\mathrm{kcal} / \mathrm{min})$ Ei: Energy expenditure at rest (kcal/min)

\section{RESULTS AND DISCUSSION}

The crackers produced in the plant is carried through four steps: spice pastes making, dough preparation, crackers forming, and drying. The company has to store sufficient amount of raw materials, work in process and finished products. Analyzing and modification of plant layout needs to consider the principles of plat layout which are: the integration of all the factors affecting production systems, minimum travel of material, smooth material flow, area utilized effectively and efficiently, work safety, and the layout is quite flexible.

\subsection{Analysis of existing layout}

The existing layout of the plant has been drawn based on the primary data collected from the industry and is given in the Figure 1.

The building has a dimension of $25.1 \mathrm{~m} \mathrm{x}$ $37.3 \mathrm{~m}$ and the various workstations are located within the building. Seasoning preparation is done in the household kitchen (23) and the material is moved from here to workstation of seasoning making (1). It takes about 22 meters of material movement. 


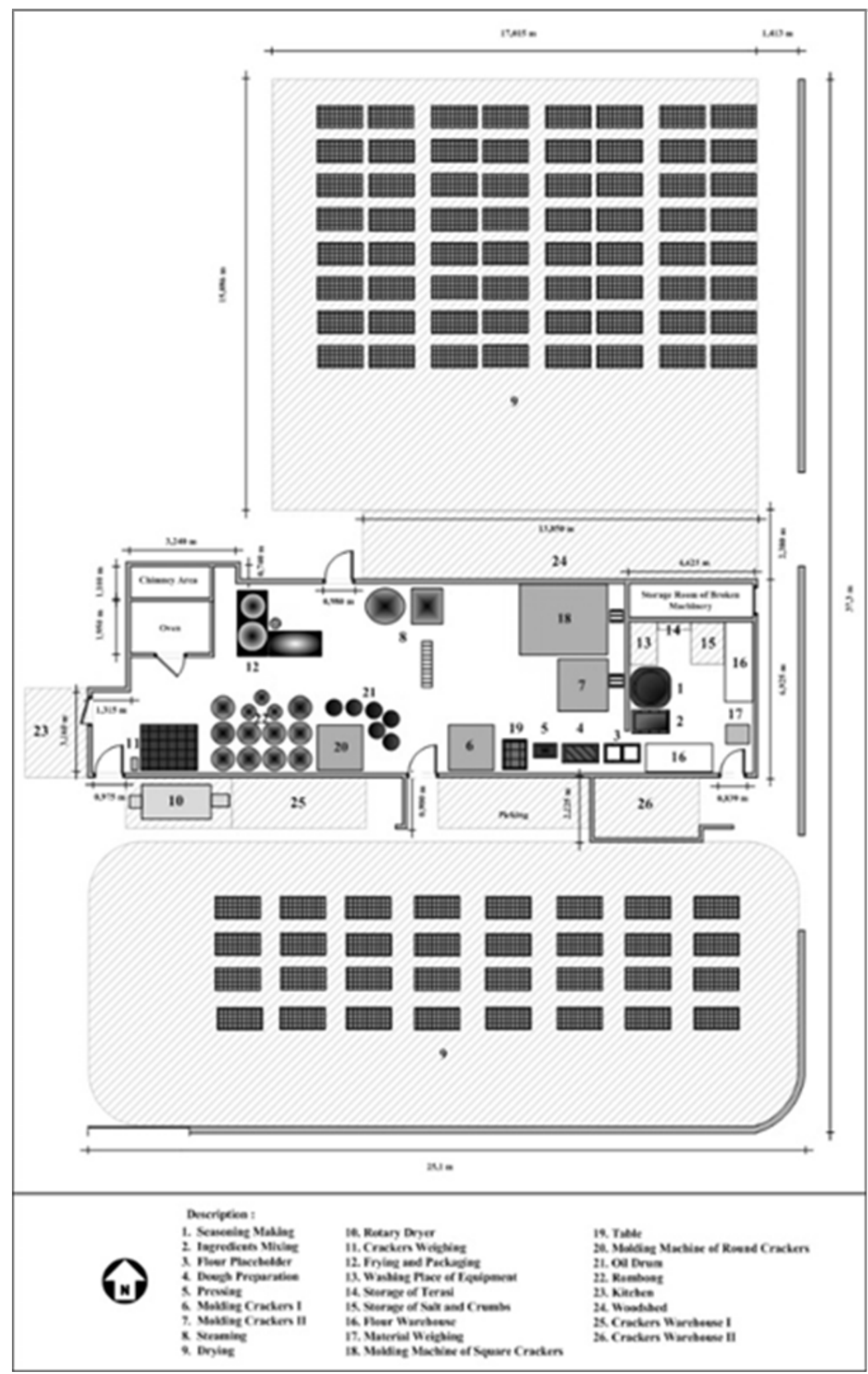

Figure 1 Existing layout of Crackers Industry

Generally, production area in small scale industry and household kitchen is not separated. This causes difficulties in a control of production system. The improper positioning of the workstation with respect to 
the production flow makes the flow of materials complicated.

The broken molding machine (18), unused table (19), unused molding machine (20) and excess containers of crackers or rombong in Indonesian (22) were placed in a production area. These production facilities are not used because the number exceeds the demand. It is necessary for recalculating the actual number of machines or equipment needed. The placement of these unnecessary production facilities could increase the distance movement of material and reduce the space utilization.

The uniqueness of the food industry compared to the non-food industry is the food safety. Inappropriate closeness between workstations i.e. washing place of equipment (13) and raw material storage $(14,15,16)$ were placed in the same room without border potentially cause cross contamination and risk to the food safety as shown in Figure 2.

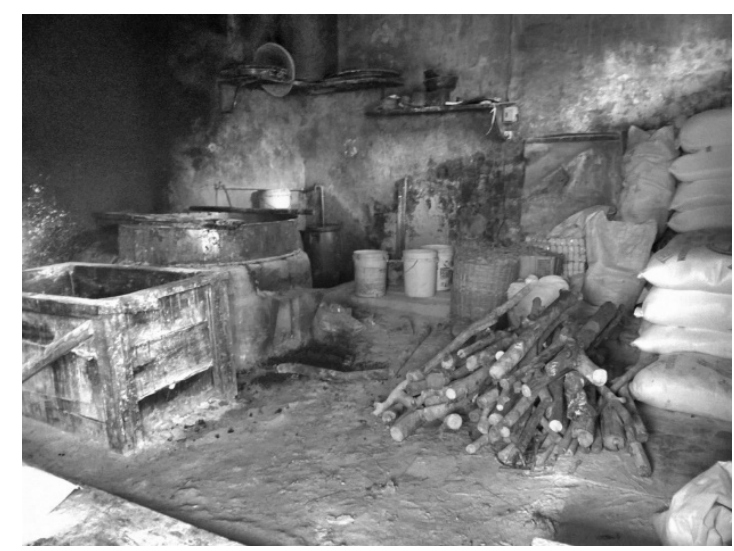

Figure 2. Washing place of equipment close to the raw material storage

The material handling audit check sheet shows the congestion due to low space availability near equipment such as in the workstation of ingredients mixing with aisle of $0.35 \mathrm{~m}$ (Fig.3). All materials handling are applied manually and some of them excess the human work load, i.e. 50-100 kg dough was moved from stirring to pressing workstation, 7 times per day at distance of $1.5 \mathrm{~m}$. The company has been facing problems that hinder the smooth material flow and it has also been observed that there is a lack of layout planning.
It has been found that conditions are affecting the entire production process.

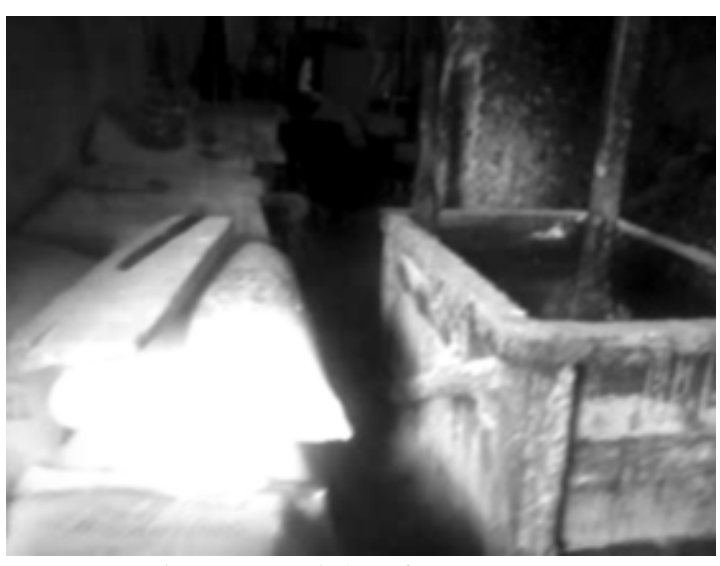

Figure 3. Aisle of 0.35 meters

\subsection{Modification of plant layout}

Based

on

the initial layout incompatibility with the principles of layout, layout modifications are carried out. The proposed layout is shown in Fig. 4.

Recalculation of actual number of machines/equipment resulted in a reduction in the amount of crackers container and molding machine into 5 and 2, respectively. To avoid risk of cross contamination, washing place of equipment is placed apart from raw material storage, especially flour storage. The broken machine and unused table are moved out of the production area. The seasoning preparation and supplied material weighing workstation are no longer done in the household kitchen. Moreover, drying space is set into one location with reduced in area.

\subsection{Performance of the proposed layout}

Figure 4 shows that modification of plant layout reduces production area to about $40 \%$. The comparison of performance between initial and proposed layout are shown in Table 1. Through modification of the design layout to accommodate the uniqueness of the food industry, the total distance between workstations of original layout and proposed layout is reduced to $42.6 \%$. The total distance traveled per day is $6,446.55 \mathrm{~m}$ for original layout and 5,064.21 $\mathrm{m}$ for proposed one. 


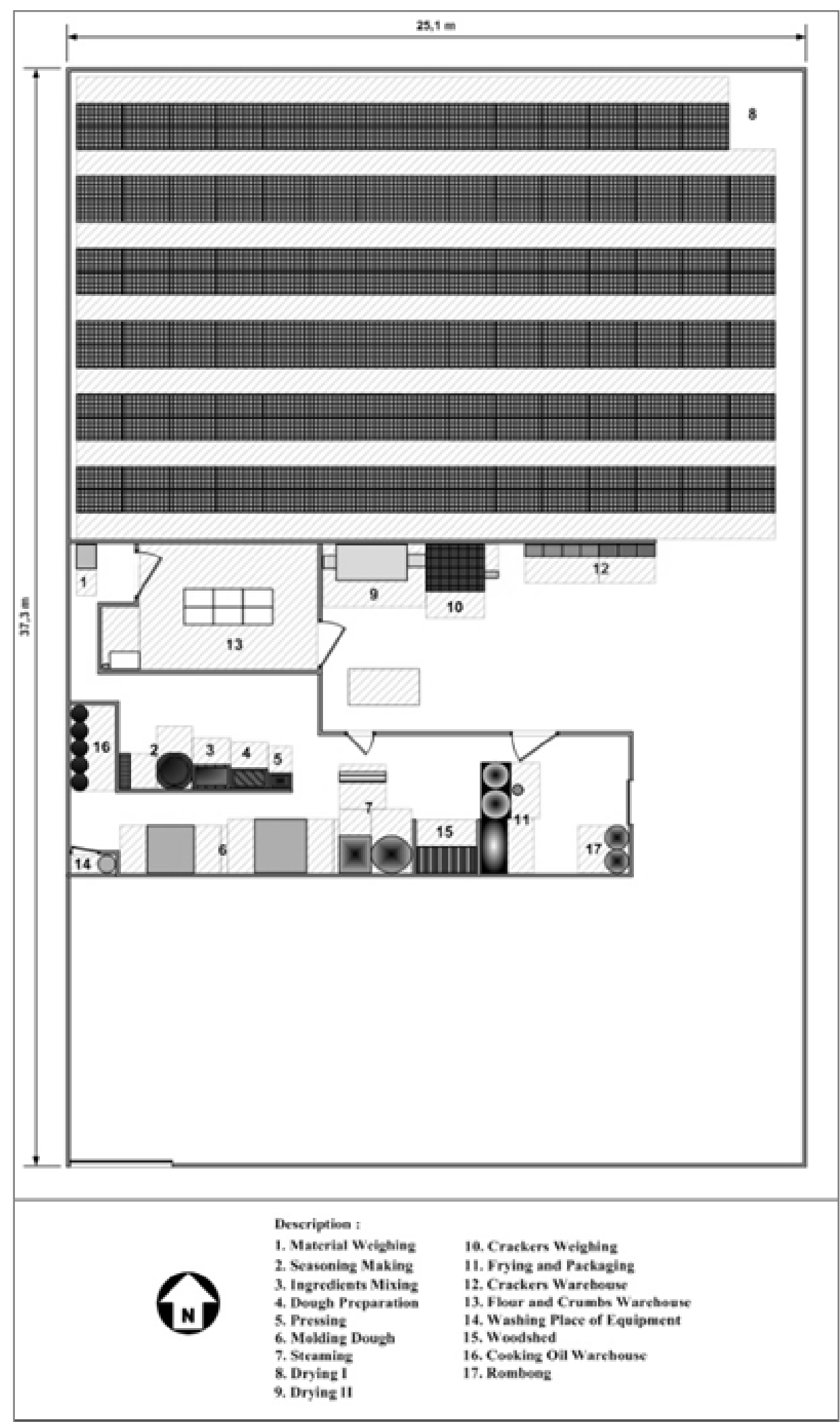

Figure 2 Proposed Layout of Crackers Industry

Materials handling activities are carried out in the cracker industry especially in the manual transfer of material. Therefore, reducing the distance decreases worker consumption energy. Energy consumption for material handling decrease to $18.46 \%$, from 
$24.1 \mathrm{kcal} / \mathrm{min}$ to $19.6 \mathrm{kcal} / \mathrm{min}$. From the food safety point of view, proposed layout has separated washing place of equipment with the raw material storage. Therefore quality of product would be ensured. Finally, productivity would be raised. Nugroho et al. (2015) proposed modification plant layout of traditional noodle industry which could increase process cycle efficiency to $15.68 \%$.

Table 1. Performance of initial and proposed layout

\begin{tabular}{|c|c|c|c|}
\hline No & Parameter & $\begin{array}{l}\text { Initial } \\
\text { layout }\end{array}$ & $\begin{array}{l}\text { Proposed } \\
\text { layout }\end{array}$ \\
\hline 1 & $\begin{array}{l}\text { Total distance } \\
\text { between } \\
\text { workstations }(\mathrm{m})\end{array}$ & 240.98 & 138.31 \\
\hline 2 & $\begin{array}{l}\text { Total distance } \\
\text { travelled per day } \\
(\mathrm{m})\end{array}$ & $6,446.55$ & $5,064.21$ \\
\hline 3 & $\begin{array}{l}\text { Energy } \\
\text { consumption for } \\
\text { material } \\
\text { handling } \\
\text { (kcal/min) }\end{array}$ & 24.1 & 19,6 \\
\hline 4 & Food safety & $\begin{array}{l}\text { Washing } \\
\text { place of } \\
\text { equipment } \\
\text { area close } \\
\text { to the raw } \\
\text { material } \\
\text { storage }\end{array}$ & $\begin{array}{l}\text { Washing } \\
\text { place of } \\
\text { equipment } \\
\text { separate } \\
\text { with the } \\
\text { raw } \\
\text { material } \\
\text { storage }\end{array}$ \\
\hline
\end{tabular}

\section{CONCLUSSIONS}

Modication layout of small scale crackers industry based on the recalculation number of machine needed, relationship between workstations and allowance decreased the distance traveled for material, energy for material handling, and improved the food safety.

\section{ACKNOWLEDGEMENT}

We would like to acknowledge the financial support Faculty of Agricultural Technology, Universitas Gadjah Mada for Research Grant No: 661/FTP-UGM/KU/2014.

\section{REFERENCES}

Bridger, R.S. 1995. Introduction to Ergonomics. McGraw-Hill Inc. Singapore.

Hasyim, M.N., Khuriyati, N., Suharno. 2014. Redesign the Layout of Golf Gloves
Industry using BLOCPLAN Algorthm (in Indonesian). Proceeding Seminar Nasional Asosiasi Profesi Teknologi Agroindustri. Yogyakarta. Universitas Gadjah Mada.

Khuriyati, N., Wagiman, Kumalasari, D. 2014. Cleaner Production Strategy for Improving Environmental Performance of Small Scale Cracker Industry. Agriculture and Agricultural Science Procedia. Vol 3, Page 102-107.

Nugroho, A., Ainuri, M., Khuriyati, N. 2015. Waste Reduction to Improve Value Stream of "Mi Lethek" Production Using Lean Manufacturing Approach (in Indonesian). Agritech, Volume 35, No.2, Page 205-211.

Tompkins, J.A., John A. White, Yavuz A. Bozer, J.M.A. Tanchoco. 2003. Facilities Planning. John Wiley \& Sons Inc. New York. 